\title{
Growth of Solidified Shell Just below the Meniscus in Continuous Casting Mold
}

\author{
Masahito HANAO, Masayuki KAWAMOTO and Akihiro YAMANAKA \\ Research and Development Laboratories, Sumitomo Metal Industries, Ltd., 16-1 Sunayama, Kamisu, Ibaraki 314-0255 Japan.
}

(Received on October 2, 2008; accepted on December 8, 2008)

\begin{abstract}
In the high speed continuous casting of hypo-peritectic steel slabs, growth of solidified shell just below the meniscus in the mold was researched. Rate of cooling and solidification was estimated on the basis of experimental results of thickness profiles of solidified shell, heat flux in the mold and dendrite arm spacing in the solidified structure beneath the surface of the slabs cast at $3-5 \mathrm{~m} / \mathrm{min}$.

As a result, it was found that there is a delaying period of solidification growth at the beginning, till the shell grows up to about $1 \mathrm{~mm}$ thick. After that, it grows in linear relation to square root of solidification time. Dealing with the thickness profiles as a function of solidification time and solidification rate was obtained by differential. Furthermore, cooling rate of the shell was estimated with this solidification rate and heat flux in the mold. This cooling rate showed good agreement with that estimated from dendrite secondary arm spacing of the slabs.

Estimated cooling rates were compared with the slabs by conventional continuous caster at $1.1-1.6 \mathrm{~m} / \mathrm{min}$ and the influence of casting speed was discussed. It resulted in that cooling rate increases with casting speed and the difference by casting speed begins to be remarkable in the period of $0.1-1 \mathrm{~s}$ for solidification time, when uneven solidification just begins to occur. This agreement was considered to be one of the reasons why uneven solidification or longitudinal surface cracking of slabs tends to occur with increase of casting speed.
\end{abstract}

KEY WORDS: continuous casting; solidification; hypo-peritectic steel; solidified shell; dendrite arm spacing; cooling rate; solidification rate; heat flux; longitudinal surface cracking.

\section{Introduction}

In the continuous casting mold, even growth of solidified shell is very important for maintaining surface quality of slabs, especially for the prevention of longitudinal surface cracking. When the solidified shell comes to have uneven thickness, what is called uneven solidification, stress by shrinkage of solidification, $\delta-\gamma$ transformation, or peritectic reaction is concentrated on the thinner and weaker part of the shell. As a result, deformation or cracking of the shell is induced there. ${ }^{1-5)}$ The thickness of solidified shell begins to be uneven at such early period that solidification time may be less than $1 \mathrm{~s}$ and the solidified shell may grow within only several millimeters. ${ }^{6}$

On the evenness of solidified shell, such casting conditions as casting speed, ${ }^{7-9)}$ carbon content in molten steel and those of alloying elements ${ }^{10,11)}$ give large influences. In any way, mild cooling has been considered to be an effective countermeasure against the uneven solidification. ${ }^{12)}$ So, the mild cooling of initial solidification has been tried by means of fine grooves on the surface of mold, ${ }^{13,14)}$ application of materials of low thermal conductivity to the mold, ${ }^{15,16)}$ decrease of coolant flow rate in the mold, ${ }^{17)}$ crystallization of the film which mold flux forms after infiltration along the mold. ${ }^{11,18-20)}$

It is necessary to estimate solidification parameters of the solidified shell in order to understand and improve the initial solidification in the mold. Heat flux in the mold is often evaluated as one of the parameters, and its behavior has been researched. ${ }^{9,21)}$ For example, heat flux increases with casting speed and longitudinal surface cracking becomes remarkable, and the critical value apparently exists in the heat flux: cracking becomes terrible when the heat flux exceeds the certain critical value. ${ }^{9}$ Effect of mild cooling with mold flux on the prevention of cracking is usually evaluated by the heat flux.

On the other hand, solidification parameters such as cooling rate or solidification rate can be obtained by research on the solidified shell, and there has already been valuable studies by A. Suzuki et al. ${ }^{22,23)}$ They measured dendrite primary or secondary arm spacing and thickness of solidified shell for high carbon or stainless steel billets, and on the basis of these experimental results, they estimated cooling rate or solidification rate of solidified shell in the mold. But even in their studies, solidification parameters have estimated only in the inner range of a billet more than $10 \mathrm{~mm}$ from the surface. That is to say, there has been little information on the cooling condition in such an early period that the solidified shell may grow only within $1 \mathrm{~mm}$ thick. Furthermore, influences of any casting conditions on the cooling rate were not discussed in their studies, neither. In order to clear up the criteria for the generation of uneven solidifi- 
cation, it is very important to estimate the cooling rate of initial solidification and to clarify some influences on it.

The authors previously tried high speed casting of hypoperitectic steel slabs in medium thickness, and succeeded in casting at $5 \mathrm{~m} / \mathrm{min}$ without longitudinal surface cracking. ${ }^{20)}$ Comparing the results with those in conventional casting at $1-3 \mathrm{~m} / \mathrm{min}$, influence of casting speed on the solidification parameters can be considered in the wider range of casting speed. So, hypoperitectic steel slabs by that high speed casting were researched on the dendrite arm spacing and thickness of solidified shell, and cooling rate in quite early period of initial solidification in the mold was estimated on the basis of the results in this study. Furthermore, the same research was conducted on the slabs cast at $1.1-1.6 \mathrm{~m} / \mathrm{min}$ by several conventional casters, and in comparison between them, influence of casting speed on cooling rate of solidified shell was discussed.

\section{Methods and Conditions}

\subsection{Casting Conditions}

Hypoperitectic steel slabs for this research were cast at $3.0-5.0 \mathrm{~m} / \mathrm{min}$ by pilot plant (caster E-1) for high speed continuous casting in Kashima Steel Works. Slabs for this research were also cast at $1.1-1.6 \mathrm{~m} / \mathrm{min}$ by two conventional slab casters (caster K-2 and K-3) in Kashima Steel Works and an experimental caster (caster E-2) at the Corpo- rate Research and Development Laboratories in Hasaki, and their results were compared with those of the high speed casting by the caster E-1. Casting conditions for each caster are listed in Table 1. Mold sizes were $90-100 \mathrm{~mm}$ thick and 800-1000 mm wide for the caster E-1 and E-2, and 235-270 $\mathrm{mm}$ thick and 1500-2300 $\mathrm{mm}$ wide for the caster K-2 and K-3. Super heat of the molten steel for the cast was commonly $12-36^{\circ} \mathrm{C}$, but $80-89^{\circ} \mathrm{C}$ only for the caster E-2 whose heat loss was more than the others because of its small heat size. In the casting by the caster E-1, thickness of solidified shell, local heat flux in the mold, and dendrite primary or secondary arm spacing were evaluated. Dendrite primary arm spacing was evaluated also in the case of the E-2, K-2 and K-3. Compositions of molten steel are listed in Table 2. Carbon content is 0.09-0.14 mass\% and Silicon, Manganese and Aluminum were added as alloying elements. Mold fluxes for the casting are listed in Table 3. The mold flux $\mathrm{C}$ was used in principle, but the mold flux $\mathrm{K}$ or $\mathrm{KZ}$ was used in the certain cases that the data of local heat flux or thickness of solidified shell were referred.

\subsection{Measurement of Thickness of Solidified Shell}

Solidified shell was observed on the longitudinal section of a slab by the caster E-1. The method is schematically shown in Fig. 1(a). Ferro-Sulfur alloy (FeS, in the following) was added to molten steel in the mold during the cast-

Table 1. Casting conditions.

\begin{tabular}{|c|c|c|c|c|}
\hline $\begin{array}{l}\text { Casting machine } \\
\text { (Heat size, ton) }\end{array}$ & $\begin{array}{c}\text { Mold size, mm } \\
\text { Thickness, width }\end{array}$ & $\begin{array}{l}\text { Casting speed, } \\
\mathrm{m} / \mathrm{min}\end{array}$ & $\begin{array}{c}\text { Super heat, } \\
\text { K }\end{array}$ & Research $^{*}$ \\
\hline E-1 $(80)$ & $90, \quad 1000$ & $3.0-5.0$ & $12-27$ & $q, d_{\text {shell }}, \lambda_{I}, \lambda_{I I}$ \\
\hline E-2 ( 2.5) & $100, \quad 800$ & 1.4 & $80-89$ & $\lambda_{I}$ \\
\hline $\mathrm{K}-2 \quad(280)$ & 235,2300 & 1.1 & 36 & $\lambda_{I}$ \\
\hline $\mathrm{K}-3 \quad(300)$ & $270, \quad 1500$ & $1.3-1.6$ & $17-26$ & $\lambda_{I}$ \\
\hline
\end{tabular}

Table 2. Alloying elements in molten steel (unit: mass\%).

\begin{tabular}{cccccc}
\hline $\mathrm{C}$ & $\mathrm{Si}$ & $\mathrm{Mn}$ & $\mathrm{P}$ & $\mathrm{S}$ & $\mathrm{Al}$ \\
\hline $0.09-0.14$ & $0.05-0.35$ & $0.30-1.45$ & $<0.022$ & $<0.007$ & $0.01-0.08$ \\
\hline
\end{tabular}

Table 3. Specifications of mold fluxes.

\begin{tabular}{cccccccc}
\hline Mold flux & \multicolumn{4}{c}{ Compositions, mass\% } & & Solidification & Viscosity at \\
& $\mathrm{T} . \mathrm{CaO} / \mathrm{SiO}_{2}$ & $\mathrm{Na}_{2} \mathrm{O}$ & $\mathrm{ZrO}_{2}$ & $\mathrm{~F}$ & Others & temperature, $\mathrm{K}$ & $1573 \mathrm{~K}, \mathrm{~Pa} \cdot \mathrm{s}$ \\
\hline $\mathrm{C}$ & 1.8 & 8.0 & - & 12.0 & $\leqq 6.0$ & 1509 & 0.04 \\
$\mathrm{KZ}$ & 1.2 & 10.0 & 3.4 & 10.0 & $\leqq 6.0$ & 1507 & 0.07 \\
\hline
\end{tabular}

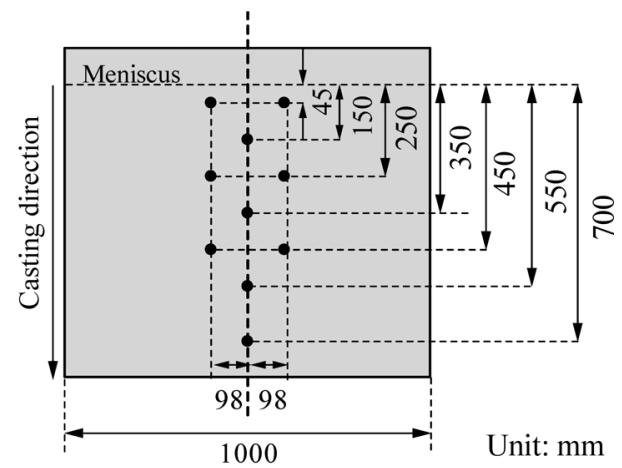

(b) Position of thermo-couples in the wide face of mold

Fig. 1. Schematic views of experimental conditions in the casting with the caster E-1. 
ing. The slab which was cast just at the moment of FeS addition was cut lengthwise after the casting, and the distribution of Sulfur content on the longitudinal section was printed. On the printing paper, the white area along the surface was regarded as the solidified shell formed before the FeS addition, and its thickness was measured by calipers.

\subsection{Evaluation of Local Heat Flux in the Mold}

Temperature in copper plate of the mold is continuously measured by thermo-couples during casting of the caster E-1. The positions of thermo-couples in the mold are shown in Fig. 1(b). They were located around the center of width and 45-700 below the meniscus level in the wide face of the mold. The average temperature in constant state of casting speed was converted to local heat flux according to the method same as the previous study. ${ }^{9}$ )

\subsection{Measurement of Dendrite Arm Spacing}

Dendrite structures near the surface of slabs were observed and primary or secondary arm spacing was measured. Samples for the observation were cut off around the center of width of slabs. In the case that primary arm spacing was measured, the sections for observation were taken parallel to the surface of slabs. In the case of secondary arm spacing, the sections were taken perpendicular to casting direction and the surface of slabs. The sections for the observation were polished and etched with picric acid. Dendrite structures on the etched sections were observed with optical microscope and taken into photographs. Dendrite primary or secondary arm spacing was measured on the photographs with calipers, and the measured length was converted to actual one by magnification. In the case of primary arm spacing measurement, a procedure of a polish, etching and observation was repeated so as to get several sections of different distances from the surface for the same dendrites.

\section{Results}

\subsection{Thickness of Solidified Shell}

As a result obtained from the casting with the caster E-1, thickness of solidified shell is shown in Fig. 2 as a function of square root of solidification time. Each data of the thickness agreed well regardless of casting speed. In the initial period from the origin to about 0.07 in $x$-axis, the thickness showed very slow growth of solidification. Then the gradi-

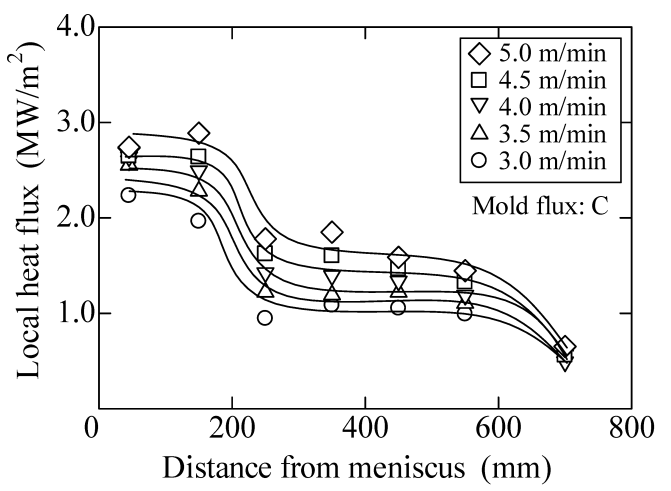

(a) At the center in width. ent of the growth increased and became linear in the second period larger than 0.07 in $x$-axis. On the assumption that solidification rate is proportional to solidification time in the first period and to square root of solidification time in the second period, ${ }^{24)}$ the thickness of solidified shell was regressed as Eqs. (1) and (2).

$$
\begin{gathered}
d_{\text {shell }}=69.7 t, \quad 0<t \leqq 0.005 \ldots . \\
d_{\text {shell }}=30.0 \sqrt{t}-1.76, \quad 0.005<t .
\end{gathered}
$$

Here, $d_{\text {shell }}$ is thickness of solidified shell (mm) and $t$ is solidification time ( $\mathrm{min})$.

At $45 \mathrm{~mm}$ below the meniscus, the thickness $d_{\text {shell }}$ is estimated to be 1-2 mm thick for the casting speed of 3.0$5.0 \mathrm{~m} / \mathrm{min}$.

\subsection{Local Heat Flux in the Mold}

Local heat flux in the mold of the caster E-1 is shown in Fig. 3. The local heat flux around the center of width is shown as a function of distance from the meniscus in Fig. 3(a), and that at $45 \mathrm{~mm}$ below the meniscus level is shown as a function of casting speed in Fig. 3(b).

In the vertical direction in the mold, local heat flux was higher in the range of $45-150 \mathrm{~mm}$ below meniscus level and gradually decreased with the distance from the meniscus level. Local heat flux increased with casting speed but exhibited same profiles regardless of casting speed.

Local heat flux at $45 \mathrm{~mm}$ below the meniscus level increased with casting speed, and it was regressed in quad-

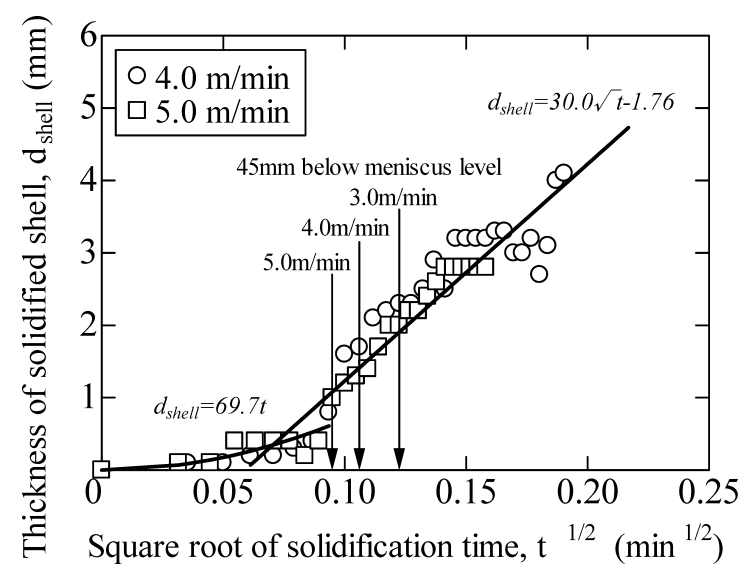

Fig. 2. Thickness of solidified shell as a function of square root of solidification time.

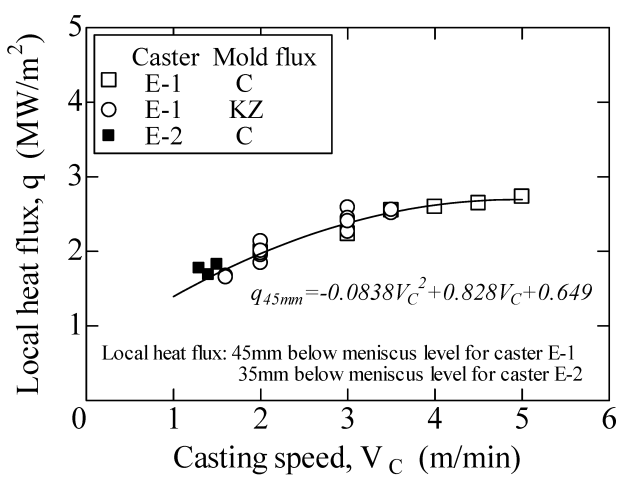

(b) At $45 \mathrm{~mm}$ below meniscus level.

Fig. 3. Local heat flux in the mold of the caster E-1. 
ratic form as an Eq. (3).

$$
q=-0.0838 V_{\mathrm{c}}^{2}+0.828 V_{\mathrm{c}}+0.649
$$

Here, $q$ is local heat flux $\left(\mathrm{MW} / \mathrm{m}^{2}\right)$ and $V_{\mathrm{c}}$ is casting speed $(\mathrm{m} / \mathrm{min})$. Because there was no data of the mold flux $\mathrm{C}$ at less than $3.0 \mathrm{~m} / \mathrm{min}$, the data of the mold flux $\mathrm{KZ}$, whose solidification temperature or crystallization of cuspidine was considered to be equivalent, was put together in the regression. Local heat flux showed same tendency regardless of the kind of mold fluxes.

Local heat flux of the casting by the caster E-2 is referred in the Fig. 3(b), as the data for the mold flux C. Though the heat flux evaluated at $35 \mathrm{~mm}$ below the meniscus level cannot be identified with that at $45 \mathrm{~mm}$, but they agreed well with each other. This agreement seems to suggests that the regression of the Eq. (3) is reasonable.

\subsection{Dendrite Structures Near the Surface of Slabs}

Dendrite structure on the section perpendicular to the casting direction and surface of a slab is shown in Fig. 4. This is in the case of a slab cast at $5.0 \mathrm{~m} / \mathrm{min}$ by the caster E-1. Primary arm of dendrite grew from the surface toward inside of a slab, and it became thicker and coarser with the growth. In the range within $1 \mathrm{~mm}$ from the surface, the structure was so fine that secondary arm of dendrite was not found clearly, but it became clear with the growth toward inside.

Dendrite structures on the section parallel to the surface of a slab by the caster E-1 are shown in Fig. 5. Here, 5 sections are shown by the distance from the surface. Common to all the sections, primary arm of dendrite was observed like lattices. The lattices became coarser with the distance from the meniscus. As shown in Fig. 6 for the slabs by the caster K-3, these lattice structures were observed in all of the samples from each caster.

\subsection{Dendrite Arm Spacing}

Dendrite secondary arm spacing near the surface of slabs by the caster E-1 is shown in Fig. 7 as a function of distance from the surface. At $1 \mathrm{~mm}$ beneath the surface, secondary arm spacing was about $20 \mu \mathrm{m}$ and it gradually increased with the distance from the meniscus. It seems that

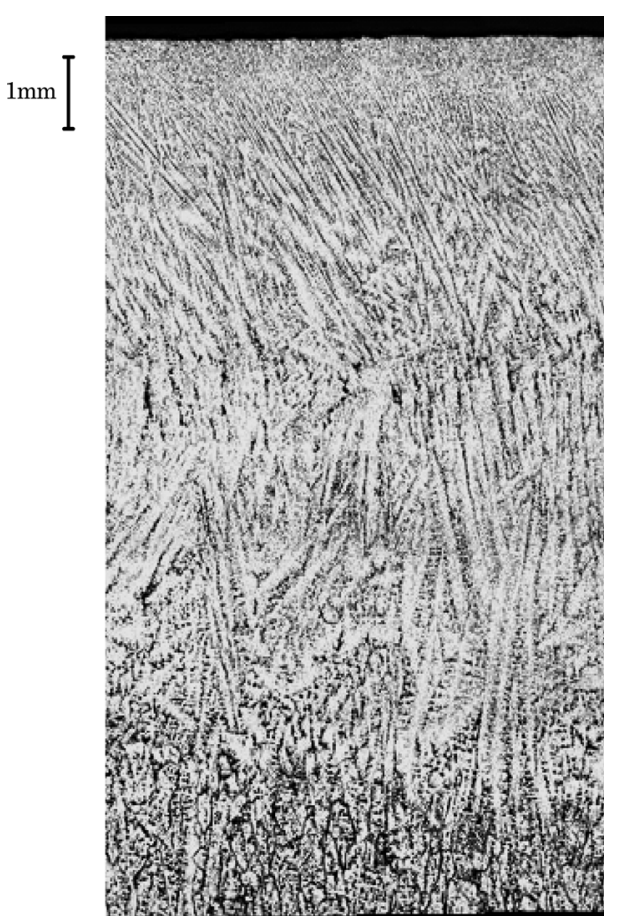

Fig. 4. Dendrite structures near the surface of a slab cast at $5.0 \mathrm{~m} / \mathrm{min}$ by caster E- 1 . The cross section is perpendicular to the casting direction and at the center of width.

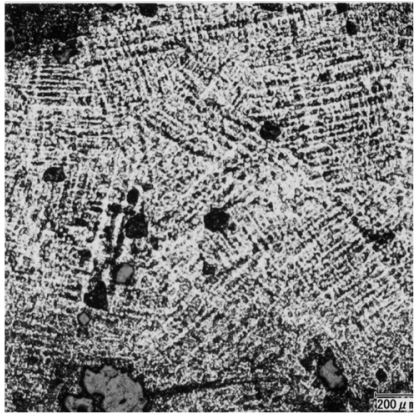

(a) $0.09 \mathrm{~mm}$ under the surface.

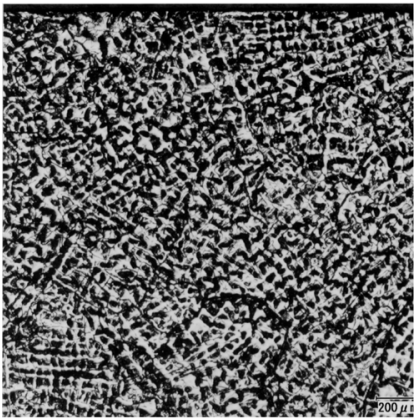

(d) $2.10 \mathrm{~mm}$ under the surface.

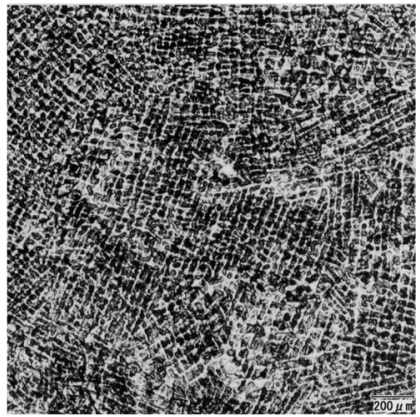

(b) $0.62 \mathrm{~mm}$ under the surface.

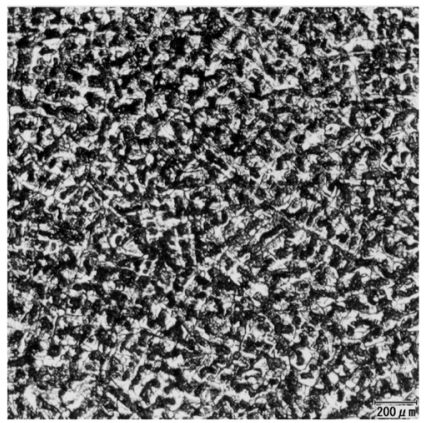

(e) $3.00 \mathrm{~mm}$ under the surface.

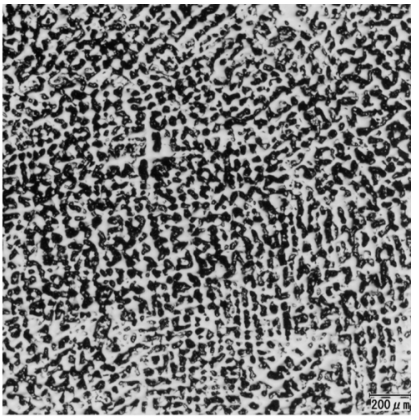

(c) $1.30 \mathrm{~mm}$ under the surface.

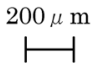

Fig. 5. Dendrite structures near the surface of a slab cast at $5.0 \mathrm{~m} / \mathrm{min}$ by caster E-1. The cross section is parallel to the surface and at the center of width 


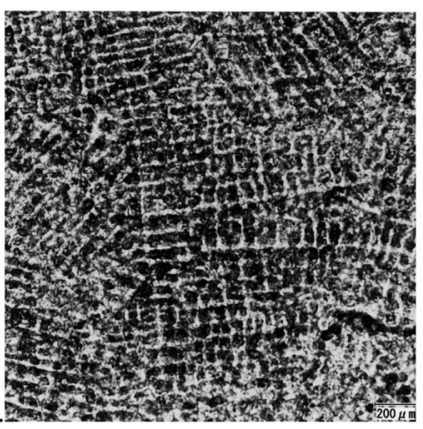

(a) $0.23 \mathrm{~mm}$ under the surface.

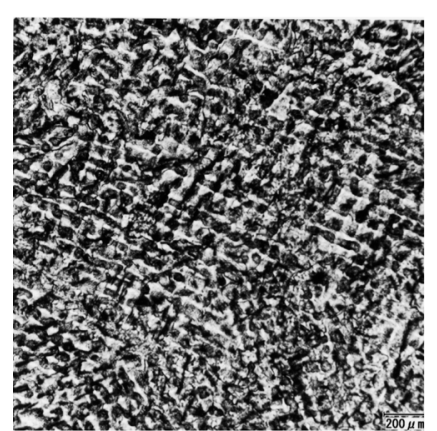

(d) $2.22 \mathrm{~mm}$ under the surface.

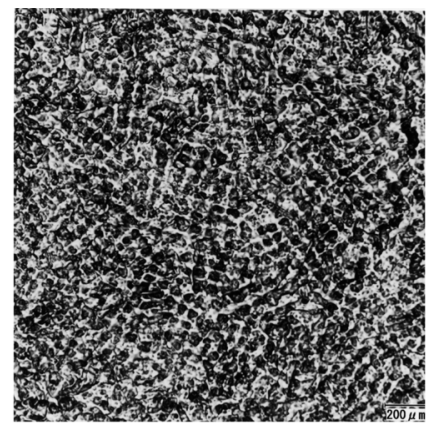

(b) $0.90 \mathrm{~mm}$ under the surface.

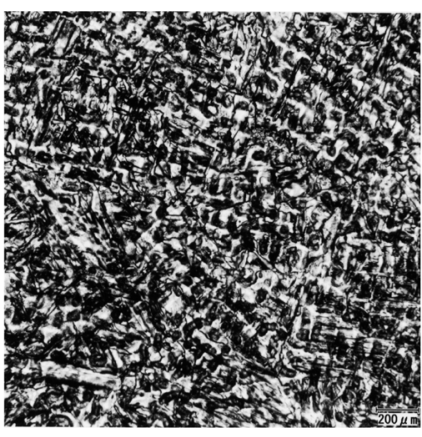

(e) $2.77 \mathrm{~mm}$ under the surface.

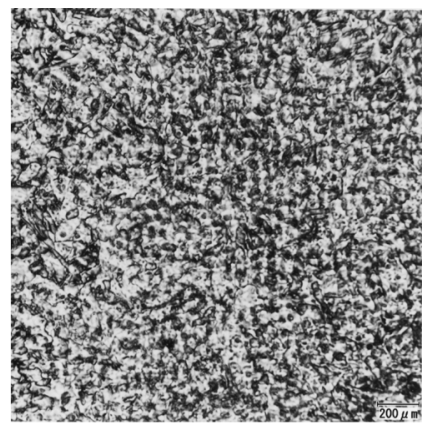

(c) $1.34 \mathrm{~mm}$ under the surface.

$200 \mu \mathrm{m}$

Fig. 6. Dendrite structures near the surface of a slab cast at $1.6 \mathrm{~m} / \mathrm{min}$ by caster $\mathrm{K}-3$. The cross section is parallel to the surface and at the center of width

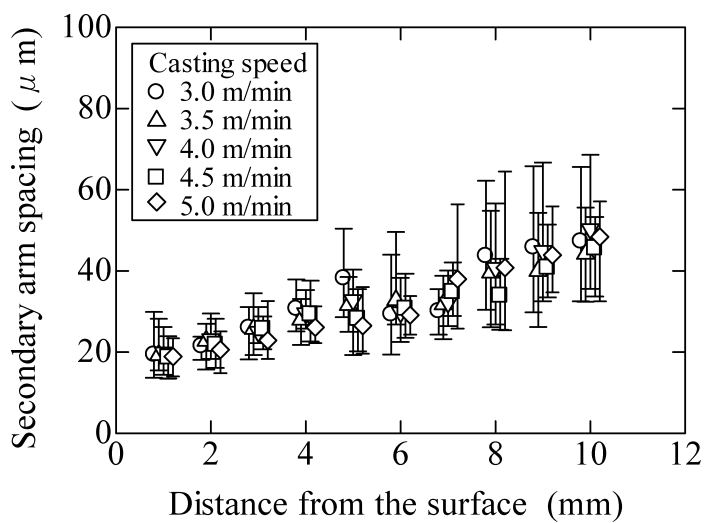

Fig. 7. Secondary arm spacing of dendrite structure near the surface of a slab by caster E-1 as a function of distance from the surface.

secondary arm spacing increased with casting speed, but the difference was little.

Dendrite primary arm spacing near the surface of slabs is shown in Fig. 8 as a function of distance from the surface. Quite near the surface, primary arm spacing was about $30 \mu \mathrm{m}$ and it gradually increased with the distance from the surface. Primary arm spacing differed by casting speed and the difference became evident with the distance from the surface, and the spacing of $1.1-1.6 \mathrm{~m} / \mathrm{min}$ was larger than that of $3.0-5.0 \mathrm{~m} / \mathrm{min}$

\section{Discussions}

\subsection{Comparison of Thickness of Solidified Shell with Literature Data}

Thickness of solidified shell shown in Fig. 2 is one of the origins of analysis in this study, so it is important to discuss

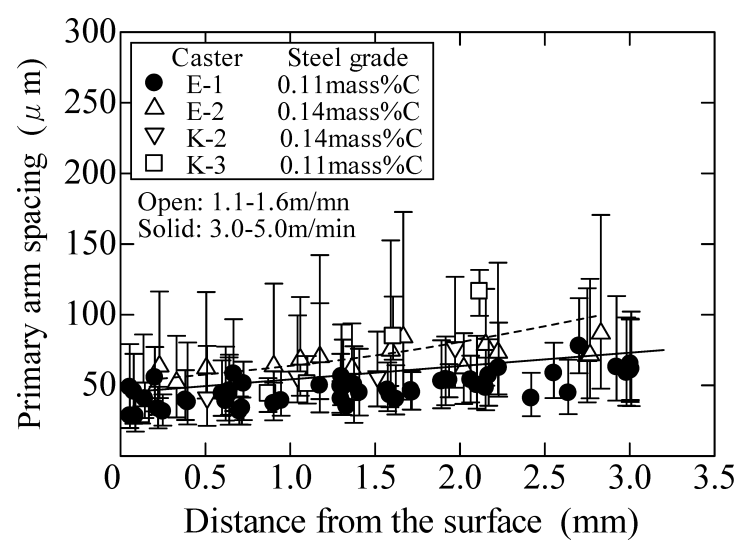

Fig. 8. Primary arm spacing of dendrite structure near the surface of a slab by caster E-1 as a function of distance from the surface.

the propriety of it. At first, it is compared with some data in previous research.

There has been several literatures ${ }^{23,25-30)}$ on the thickness of solidified shell since about 1970, when the continuous casting was becoming to be a major method of industrial production of steel cast. The data in those literatures are listed in Table 4 and shown in Fig. $4{ }^{23,25-30)}$ All of them were given as the expression of $d_{\text {shell }}=k \sqrt{t}+a$ rather than $d_{\text {shell }}=k \sqrt{t}$ for the thickness in the mold. The gradient $k$ is solidification coefficient $\left(\mathrm{mm} / \mathrm{min}^{0.5}\right)$ and reported to be in the range of 18.4-38.0. The $y$-axis intercepts $a$ are reported to be in the range from -8.6 to -0.86 and these negative values suggest that there is a delaying period at the beginning of solidification. The $x$-axis intercepts for the most of them are around 0.1 in square root of solidification time.

Thickness of solidified shell in this study is also shown in Fig. 9, compared with those previous data listed in Table 
Table 4. Literature data on thickness of solidified shell in the mold.

\begin{tabular}{|c|c|c|c|c|c|}
\hline Thi & $\begin{array}{l}\text { Mold size } \\
\text { hickness, width } \\
\quad(\mathrm{mm})\end{array}$ & $\begin{array}{l}\text { Casting speed } \\
\qquad(\mathrm{m} / \mathrm{min})\end{array}$ & $\begin{array}{l}\text { Steel grade } S \\
(\text { mass } \% C)\end{array}$ & $\begin{array}{l}\text { Super heat } \\
\text { (K) }\end{array}$ & $\begin{array}{l}\text { Thickness of solidified shell } \\
\text { or solidification coefficient } \\
\qquad\left(\mathrm{mm} \text { or } \mathrm{mm} / \mathrm{min}^{1 / 2}\right)\end{array}$ \\
\hline N. Nagaoka et al. ${ }^{25)}$ & 200,1600 & $0.55-0.65$ & 0.15 & - & $d_{\text {shell }}=19.1 \sqrt{t}-2.4$ \\
\hline A. Suzuki et al. ${ }^{23)}$ & 110,110 & - & High carbon & $45-55$ & $\begin{aligned} d_{\text {shell }} & =k \sqrt{t}-a \\
k & =34.7-38.0 \\
a & =2.7-3.2\end{aligned}$ \\
\hline S. Okano et al. ${ }^{26)}$ & 260,1890 & 0.65 & Middle carbon & - & $d_{\text {shell }}=18.4 \sqrt{t}-1.5$ \\
\hline T. Mori et al. ${ }^{27)}$ & 230,1600 & - & - & - & $d_{\text {shell }}=23.92 \sqrt{t}-0.86$ \\
\hline H. Fujii et al. ${ }^{28)}$ & 250,2100 & 0.65 & Low carbon & 20 & $d_{\text {shell }}=28.3 \sqrt{t}-8.6$ \\
\hline K. Narita et al. ${ }^{29)}$ & 230,1600 & 0.65 & Low carbon & - & $d_{\text {shell }}=27.5 \sqrt{t}-2.8$ \\
\hline M. Suzuki et al. ${ }^{30)}$ & 220,1550 & $2.0-2.5$ & Low carbon & $25-30$ & $d_{\text {shell }}=23.0 \sqrt{t}-2.72$ \\
\hline
\end{tabular}

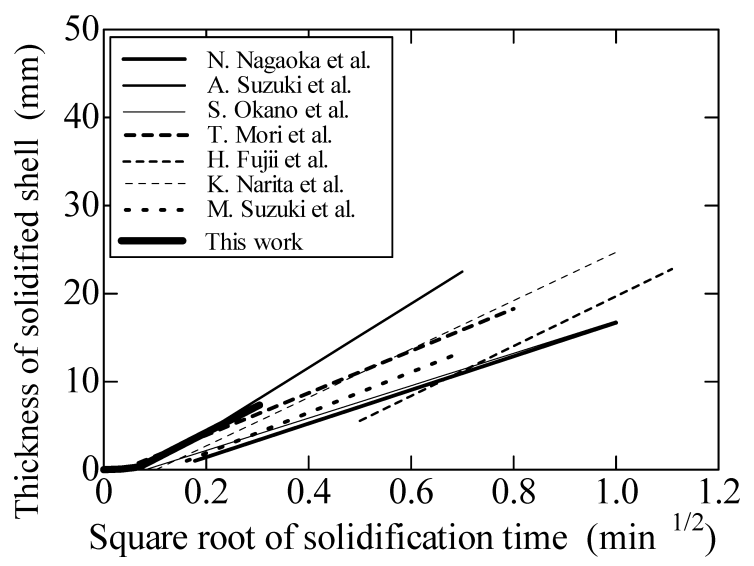

Fig. 9. Thickness of solidified shell as a function of square root of solidification time.

4. The $k$ value of 30.0 in this study is within the range of previous data. The delaying period at the beginning of solidification continues to about 0.1 in square root of solidification time, and this point agrees with the previous data. As a consequence, the thickness of solidified shell in this study is considered to be reasonable.

In this study, thickness of solidified shell was evaluated only in the range that square root of solidification time was less than 0.3. But most of the previous data shown in Table 4 suggest that the thickness of solidified shell maintains its linearity against square root of solidification time even to the lower end of the mold, so it was supposed that the Eq. (2) can be applied in the whole range of the mold in this study.

\subsection{A Delaying Period at the Beginning of Solidifica- tion}

As compared with that all of the previous data on the thickness of solidified shell were evaluated in the second period when the shell grows thicker than several millimeters, the thickness in this study was evaluated not only in that period but also in the delaying period within $1 \mathrm{~mm}$ of the thickness. This progress is owing to the high casting speed of $3.0-5.0 \mathrm{~m} / \mathrm{min}$. In the case of $1 \mathrm{~m} / \mathrm{min}$, according to Eq. (2), it takes only $8.5 \mathrm{~mm}$ from the meniscus for the

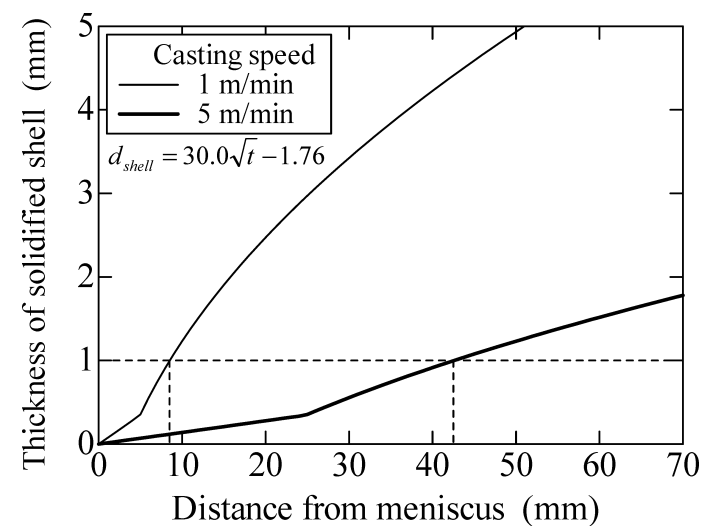

Fig. 10. Calculated thickness of solidified shell in comparison of casting speed.

solidified shell to move downward to be $1 \mathrm{~mm}$ thick. But on the other hand, it takes $42.5 \mathrm{~mm}$ in the case of $5 \mathrm{~m} / \mathrm{min}$, as shown in Fig. 10. So, the profile of the solidified shell was enabled to be observed and measured in the longer distance as the casting speed increases, as if it was magnified in the casting direction. This is the reason why the delaying period at the beginning of solidification became evident in this study.

For the reasons of the delaying, convection in the molten steel, ${ }^{24}$ thermal resistance between mold and solidified shell ${ }^{24)}$ or super heat ${ }^{31)}$ can be considered. Especially, mold flux film may have large influence on the solidification in this delaying period, through its thickness or crystallization. Solidified shell in the delaying period is very thin, so it is difficult to evaluate the difference in the thickness by mold flux. But research on this theme is a very important subject in the future.

\subsection{Estimation of Cooling Rate of Solidified Shell}

Cooling rate is a very important parameter for understanding the formation of the solidified shell, but there have been few reports on the cooling rate of actual casts by continuous casting. ${ }^{23)}$ Even the precious report by A. Suzuki, ${ }^{23)}$ the cooling rate was estimated only in the range more than $20 \mathrm{~mm}$ inner from the surface of billets. Cooling rate has never been estimated just near the surface of the casts. So, 
in this study, estimation of the cooling rate is tried for the solidified shell within $10 \mathrm{~mm}$ thick.

There are two ways to estimate the cooling rate of the solidified shell, as schematically shown in Fig. 11.

One way is to estimate from local heat flux and solidified shell thickness in the mold. Cooling rate $R(\mathrm{~K} / \mathrm{min})$ is related to temperature gradient $G(\mathrm{~K} / \mathrm{mm})$ and solidification rate $V(\mathrm{~mm} / \mathrm{min})$ of the solidified shell as expressed in Eq. (4).

$$
R=G V \text {. }
$$

$G$ is related to local heat flux $q$ by Eq. (5).

$$
G=\frac{q}{\lambda}
$$

Here, $\lambda(\mathrm{W} / \mathrm{m} \mathrm{K})$ is thermal conductivity of $\delta$-iron and supposed to be $33^{32)}$ in this study.

$V$ is given by Eq. (6) or (7), as the differentials of Eq. (1) or (2), respectively.

$$
\begin{gathered}
V=\frac{\partial d_{\text {shell }}}{\partial t}=69.7, \quad 0<t \leqq 0.005 \\
V=\frac{\partial d_{\text {shell }}}{\partial t}=\frac{30.0}{2 \sqrt{t}}, \quad 0.005<t
\end{gathered}
$$

So $R$ can be estimated on the basis of the results on $q$ and $d_{\text {shell }}$ mentioned above.

On the other hand, $R$ can be obtained by another way. A.

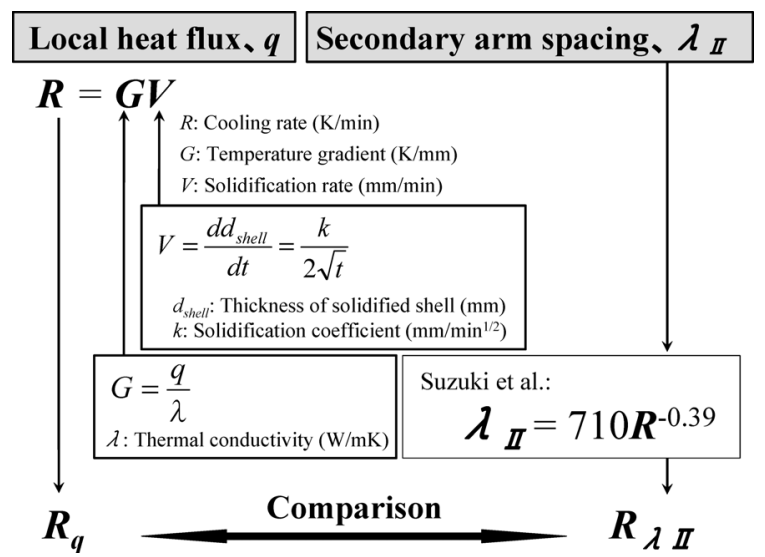

Fig. 11. Estimating methods of cooling rate of solidified shell in the case of caster E-1.

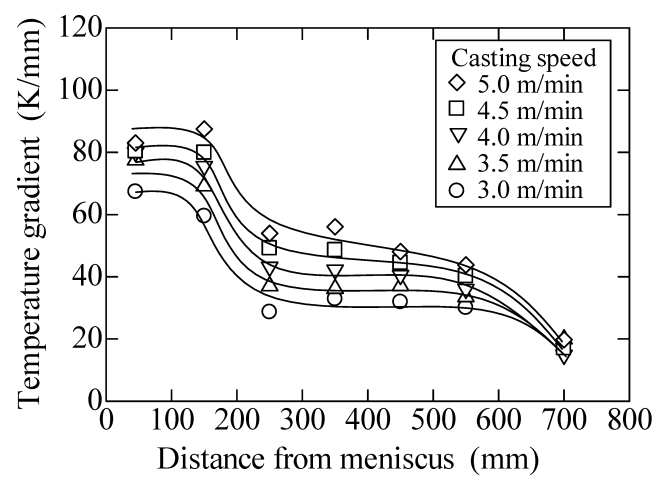

(a) At the center of width
Suzuki reported the relation between $\lambda_{\mathrm{II}}(\mu \mathrm{m})$ and $R$ as an Eq. (8). ${ }^{33)}$

$$
\lambda_{\mathrm{II}}=710 R^{-0.39}
$$

So $R$ can also be obtained from the experimental results of secondary arm spacing in this study (Fig. 7).

In this way, the cooling rate $R$ is estimated in both of two ways and those results are verified by comparison with each other in this study.

\subsubsection{Cooling Rate Derived from Local Heat Flux and Solidification Rate}

Solidification rate $V$, expressed as Eq. (6) or (7), is shown in Fig. 12. In the delaying period, solidification rate is constant at about $70 \mathrm{~mm} / \mathrm{min}$, and it suddenly increased to about $200 \mathrm{~mm} / \mathrm{min}$, then it gradually decreased with procedure of solidification.

Temperature gradients $G$ in the solidified shell are shown in Figs. 13(a) and 13(b). Temperature gradient $G$ has a maximum at $45 \mathrm{~mm}$ below meniscus level as shown in Fig. 13(a) and it increases with casting speed as shown in Fig. 13(b), as well as local heat flux.

Cooling rate $R$ can be calculated by the product of solidification rate $V$ and temperature gradient $G$ at each position of thermo-couples in the mold. The result is shown in Fig. 14 as a function of thickness of solidified shell. Here, the thickness of solidified shell is assumed to be distance from the surface of the casts. At $45 \mathrm{~mm}$ below the meniscus in the mold, when the solidified shell grows to be several

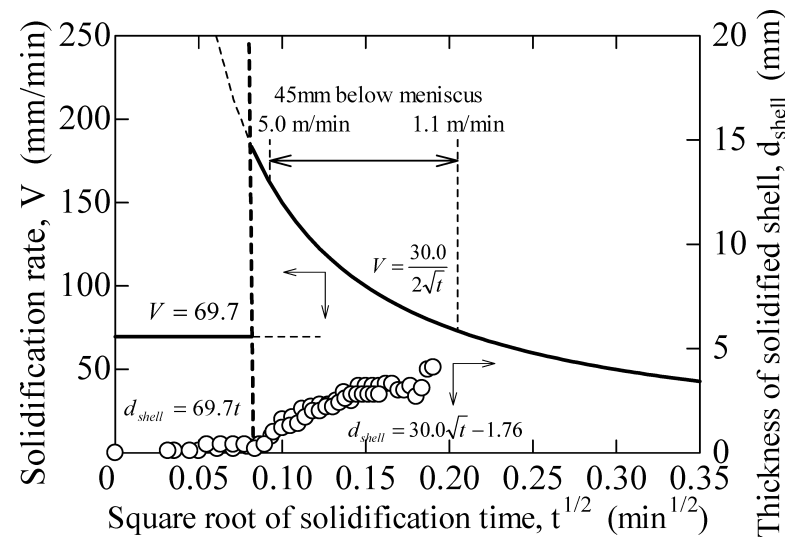

Fig. 12. Solidification rate $V$ as a function of square root of solidification time $t$.

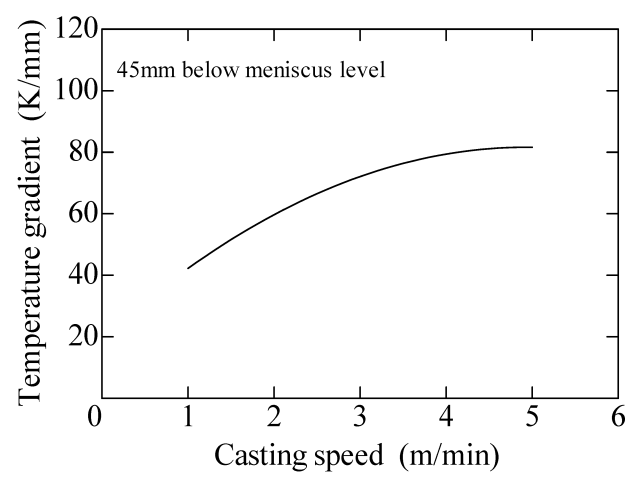

(b) At $45 \mathrm{~mm}$ below meniscus level.

Fig. 13. Temperature gradient $G$ in solidified shell. 


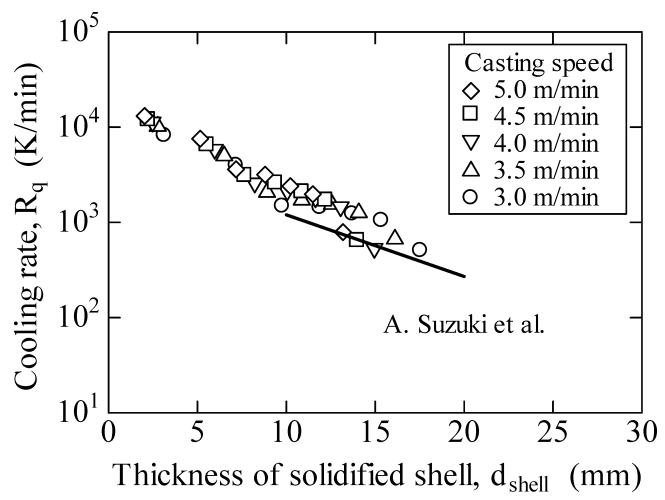

Fig. 14. Cooling rate $R_{\mathrm{q}}$ as a function of thickness of solidified shell.

millimeters thick, the cooling rate $R_{\mathrm{q}}$ is estimated about $10^{4} \mathrm{~K} / \mathrm{min}$. The cooling rate $R_{\mathrm{q}}$ decreases with further growth of solidified shell. The cooling rate $R_{\mathrm{q}}$, estimated in this study, agrees well with that by A. Suzuki, ${ }^{23)}$ which were estimated in the range of $10-20 \mathrm{~mm}$ for the thickness of solidified shell. In other words, it is confirmed in this study that the cooling rate by A. Suzuki can be extrapolated toward the surface and the meniscus.

\subsubsection{Comparison of $R_{\mathrm{q}}$ with the Cooling Rate $R_{\lambda \mathrm{II}}$ Esti-} mated from Dendrite Secondary Arm Spacing

Distance from the meniscus $l(\mathrm{~m})$, in the mold is related to the thickness of solidified shell $d_{\text {shell }}$ by Eq. (1) or (2), because solidification time $t$ in the Eq. (1) or (2) is expressed with $l$ and casting speed $V_{\mathrm{c}}$ as Eq. (9).

$$
t=\frac{l}{V_{\mathrm{c}}}
$$

So, the cooling rate $R_{\mathrm{q}}$ at each position of thermo-couples can be compared with $R_{\lambda \mathrm{II}}$ that estimated by dendrite secondary arm spacing measured at the corresponding thickness of solidified shell.

The result of comparison is shown in Fig. 15. The cooling rate $R_{\mathrm{q}}$ agrees well with the another, $R_{\lambda \mathrm{II}}$. This agreement suggests that the estimation of cooling rate $R_{\mathrm{q}}$ is reasonable. $R_{\mathrm{q}}$ is considered to be cooling rate $R$ in the following discussion.

Relation between dendrite secondary arm spacing and cooling rate is shown in Fig. 16. They exhibit a linear relation in logarithm, and Eq. (10) is given as the result of regression. The result agrees well with that by A. Suzuki as expressed in Eq. (8), as shown in Fig. 16, although they are different in numerical formula.

$$
\lambda_{\mathrm{II}}=367 R^{-0.31}
$$

\subsection{Influence of Casting Speed on Cooling Rate in the Initial Solidification}

As shown in Fig. 4, the dendrite structure within $1 \mathrm{~mm}$ from the surface of slabs was so fine that the secondary arm can not be observed clearly and its spacing can not be measured. On the other hand, the primary arm showed clear and latticed arrangement even within $1 \mathrm{~mm}$ from the surface, as shown in Figs. 5 and 6. By means of primary arm spacing, the cooling rate can be estimated quite near the

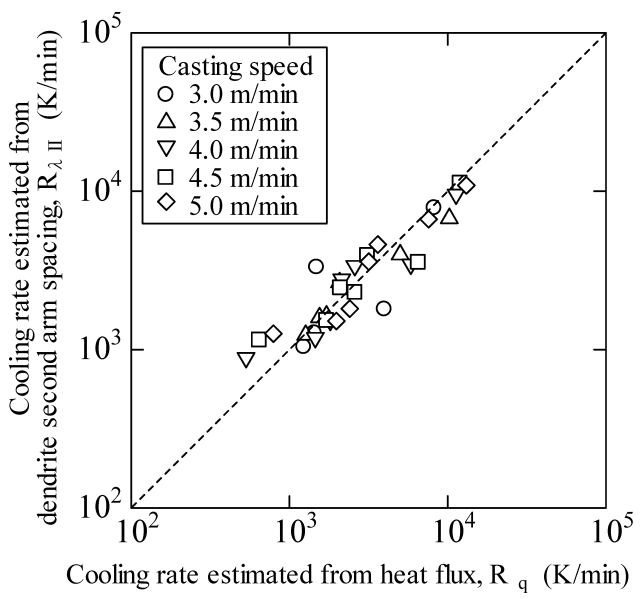

Fig. 15. Comparison between cooling rate $R_{\mathrm{q}}$ and $R_{\lambda I I}$.

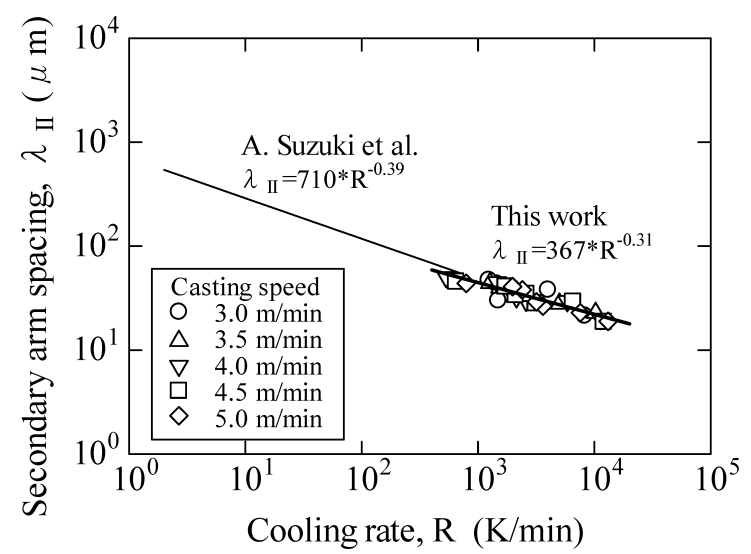

Fig. 16. Dendrite secondary arm spacing as a function of cooling rate.

surface, where the estimation by secondary arm spacing is difficult.

The method in this study is schematically shown in Fig. 17. First, dendrite primary arm spacing is measured at the position where the distance from the surface is equivalent to the thickness of solidified shell at $45 \mathrm{~mm}$ below the meniscus. Secondly, the primary arm spacing is regressed as a function of cooling rate. Then, cooling rate of the solidified shell of less than $1 \mathrm{~mm}$ thickness can be derived from the primary arm spacing.

Relation between dendrite primary arm spacing and cooling rate is shown in Fig. 18. In the range of $10^{3}-$ $10^{4} \mathrm{~K} / \mathrm{min}$ in the cooling rate, they show a linear relation in logarithm, and the regressed formula is derived as Eq. (11).

$$
\lambda_{\mathrm{I}}=1.5 \times 10^{5} R^{-0.867}
$$

Here, $\lambda_{\mathrm{I}}$ is primary arm spacing $(\mu \mathrm{m})$.

There has been few data of the primary arm spacing at such large cooling rate as $10^{3}-10^{4} \mathrm{~K} / \mathrm{min}$, but the data in this study exist in the extrapolation of the data by T. Edvardsson. ${ }^{34)}$ However, the index of -0.867 in this study is much smaller than -0.200 or -0.311 by $\mathrm{T}$. Edvardsson. The reason for this difference is not certain, but it seems that absorption between primary dendrites occurs in their growing process under intensive cooling state, like Ostward ripening of precipitates, ${ }^{35}$ ) and the absorption makes the 


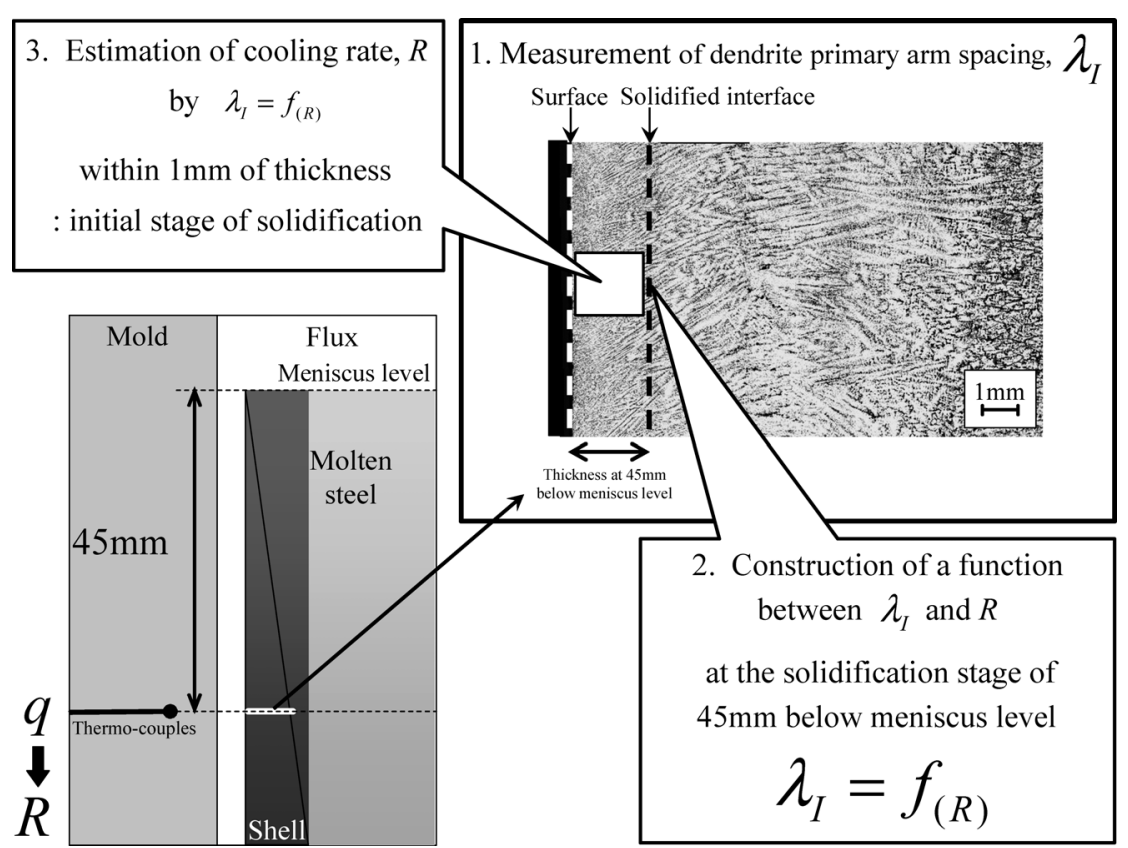

Fig. 17. A schematic view of the procedure for estimation of cooling rate at the initial stage of solidification.

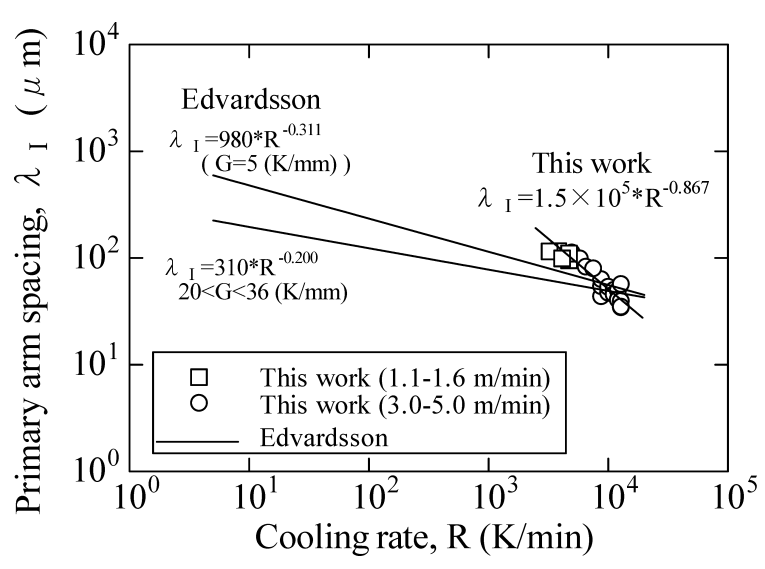

Fig. 18. Dendrite primary arm spacing as a function of cooling rate.

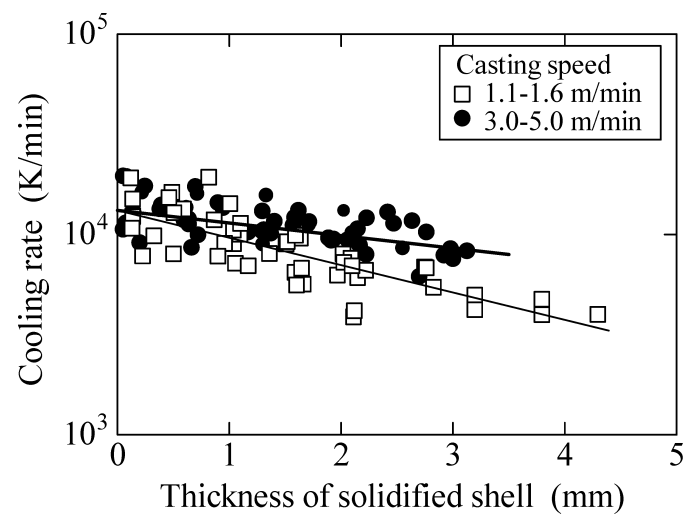

Fig. 19. Influence of casting speed on cooling rate of solidified shell.

growth of the dendrites rapid, apparently.

The estimated result of cooling rate is shown in Fig. 19. Here, the distance from the surface to the position where primary arm spacing was measured is regarded as the thickness of solidified shell. The cooling rate is estimated to be

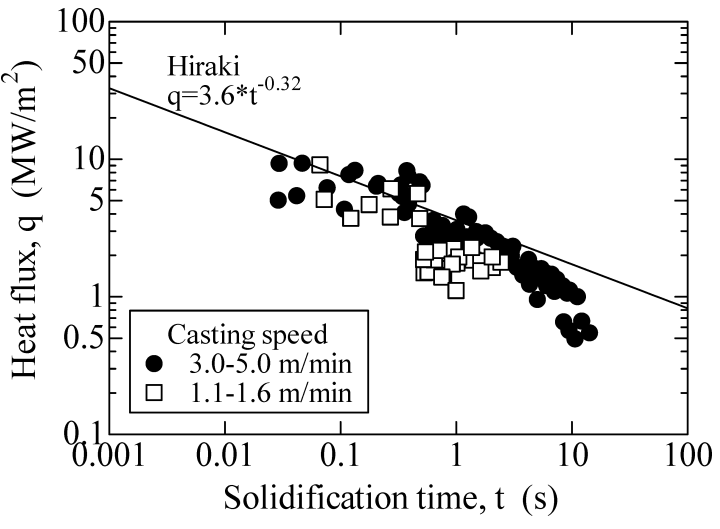

Fig. 20. Influence of casting speed on the relation between heat flux and solidification time.

about $10^{4} \mathrm{~K} / \mathrm{min}$ at the initiation of the solidification in the mold. In comparison of the cooling rate of $3-5 \mathrm{~m} / \mathrm{min}$ with that of $1.1-1.6 \mathrm{~m} / \mathrm{min}$, the difference between them is not clear just at the surface, but the cooling rate of 3-5 $\mathrm{m} / \mathrm{min}$ becomes larger and the difference between them becomes remarkable with the solidification proceeds toward the inside.

The cooling rate shown in Fig. 19 can be converted in heat flux and the thickness of solidified shell in solidification time. The relation between the heat flux and the solidification time is shown in Fig. 20. The relation of Eq. (12), which is a result of regression of previous data by various casting and fundamental experiments in the wide range of solidification time ${ }^{36,37)}$ is also shown as a reference in this figure.

$$
q=3.6 t^{-0.32}
$$

The data of heat flux in this study agrees well with Eq. (12). The difference in heat flux by casting speed becomes remarkable in the period of $0.1-1 \mathrm{~s}$. Uneven solidification is reported to occur after $0.1 \mathrm{~s}$ of solidification time, too. ${ }^{20,36)}$ These periods just coheres with each other. On account of 
these phenomena, it seems that, the reason why longitudinal surface cracking becomes remarkable with the increase of casting speed is that heat flux from the solidified shell increases with casting speed, especially at just the initial stage of uneven solidification. Thus, this increase of heat flux with casting speed promotes the uneven solidification.

The results shown in Figs. 19 and 20 suggests that it is possible for the cooling rate to differ by casting speed, in spite of same thickness of solidified shell and same solidification time. The reason for this phenomenon is considered to be the change in the thickness of flux film or air gap which exists outside the solidified shell. Change in the heat flux at $1 \mathrm{~s}$ of solidification time in the Fig. 20 corresponds to the that in the thickness of flux film or air gap of about $\pm 20 \%$ from the thickness at $3.0 \mathrm{~m} / \mathrm{min}$.

\section{Conclusions}

In the high speed continuous casting of hypo-peritectic steel slabs, growth of solidified shell just below the meniscus in the mold was researched. On the basis of experimental results of thickness profiles of solidified shell, heat flux in the mold and dendrite arm spacing in the solidified structure beneath the surface of the slabs cast at 3-5 $\mathrm{m} / \mathrm{min}$ cooling was estimated. Furthermore, similar research was tried on the slabs cast at $1.1-1.6 \mathrm{~m} / \mathrm{min}$ by several conventional casters, in terms of comparison.

The results are as follows:

(1) There is a delaying period of solidification at the beginning of solidification just below the meniscus in the mold. After that, in secondary period, the solidified shell grows faster and its thickness increases in linear relation to square root of solidification time, as known generally. Thickness of solidified shell is expressed in the following equation as a function of solidification time.

$$
\begin{gathered}
d_{\text {shell }}=69.7 t, \quad 0<t \leqq 0.005 \\
d_{\text {shell }}=30.0 \sqrt{ } t-1.76, \quad 0.005<t
\end{gathered}
$$

(2) In the proceeding of solidification, cooling rate comes to differ by casting speed in such an early period that solidification time is $0.1-1 \mathrm{~s}$, when uneven solidification also begins to occur. In this period, cooling rate or heat flux from the shell increases with casting speed. This phenomenon seems to be a reason why longitudinal surface cracking tends to occur with increase of casting speed. That difference of cooling rate by casting speed can be induced by the change in the thickness of flux film or air gap outside the solidified shell, in spite of same solidification time and thickness of solidified shell.

(3) Dendrite secondary arm spacing near the surface of slabs can be estimated as a function of cooling rate in the larger range than previous studies. The cooling rate of this study exists in the extrapolation from the previous data by A. Suzuki et al. and they show good agreement with each other.

$$
\lambda_{\mathrm{II}}(\mu \mathrm{m})=367 R^{-0.31}, \quad 10^{3} \leqq R(\mathrm{~K} / \mathrm{min}) \leqq 10^{4}
$$

\section{REFERENCES}

1) S. N. Singh and K. E. Blazek: J. Met., 26 (1974), 17.

2) N. Miyasaka, S. Hiraoka, O. Kitamura, T. Ohno, T. Ando and T. Ohashi: Tetsu-to-Hagané, 64 (1976), S663.

3) A. Grill and J. K. Brimacombe: Ironmaking Steelmaking, 2 (1976), 76.

4) Y. Sugitani and M. Makamura: Tetsu-to-Hagané, 65 (1979), 1702.

5) T. Matsumiya, T. Saeki, J. Tanaka and T. Ariyoshi: Tetsu-to-Hagané, 68 (1982), 1782.

6) Y. Shirai, H. Ichihashi, M. Yoshihara, Y. Sugitani and N. Yoshida: CAMP-ISIJ, 2 (1989), 306.

7) H. Nakato, M. Ozawa, K. Kinoshita, Y. Habu and T. Emi: Tetsu-toHagané, 67 (1981), 1200.

8) T. Sakuraya, T. Emi, T. Imai, K. Emoto and M. Kodama: Tetsu-toHagané, 67 (1981), 1220.

9) T. Kanazawa, S. Hiraki, M. Kawamoto, K. Nakai, K. Hanazaki and T. Murakami: Tetsu-to-Hagané, 83 (1997), 701.

10) T. Saeki, S. Ohguchi, S. Mizoguchi, T. Yamamoto, H. Misumi and S. Tsuneoka: Tetsu-to-Hagané, 68 (1982), 1773.

11) T. Mochida, S. Kohriyama, S. Itoyama, T. Yamashita, M. Suzuki and Y. Kishimoto: CAMP-ISIJ, 20 (2007), 851.

12) Y. Sugitani, M. Nakamura and T. Watanabe: Tetsu-to-Hagané, 67 (1981), 1508.

13) K. Nakai, T. Sakashita, M. Hashio, M. Kawasaki, K. Nakajima and Y. Sugitani: Tetsu-to-Hagané, 73 (1987), 498.

14) H. Murakami, M. Suzuki, T. Kitagawa and S. Miyahara: Tetsu-toHagané, 78 (1992) 105.

15) A. Yamauchi, S. Itoyama, Y. Kishimoto, H. Tozawa and K. Sorimachi: ISIJ Int., 42 (2002), 1094.

16) T. Watanabe: CAMP-ISIJ, 14 (2001), 153.

17) J. Nagai, M. Ohnishi, T. Yamamoto, K. Hirayama, S. Ohto and T. Fujiyama: Tetsu-to-Hagané, 69 (1983), S158.

18) K. Ichikawa, A. Morita and Y. Kawabe: Shinagawa Tech. Rep., 36 (1993), 283.

19) K. Watanabe, M. Suzuki, K. Murakami, H. Kondo, A. Miyamoto and T. Shiomi: Tetsu-to-Hagané, 83 (1997), 115.

20) M. Hanao, M. Kawamoto, M. Hara, T. Murakami, H. Kikuchi and K. Hanazaki: Tetsu-to-Hagané, 88 (2002), 23.

21) J. Fukuda, T. Kondo and K .Tsutsumi: CAMP-ISIJ, 5 (1992), 281.

22) A. Suzuki, T. Suzuki and T. Nozaki: Tetsu-to-Hagané, 55 (1969), S110.

23) A. Suzuki, T. Suzuki, S. Mitsushima and Y. Shibata: Tetsu-toHagané, 56 (1970), S427.

24) M. C. Flemings: Solidification Processing, Mcgraw-Hill Book Company, New York, (1974), 17.

$25)$ N. Nagaoka, K. Iwamoto, G. Usui, S. Nemoto and Y. Ohkawa: Tetsuto-Hagané, 55 (1969), S109.

26) S. Okano, T. Nishimura, H. Ooi and T. Chino: Tetsu-to-Hagané, 61 (1975), 2982.

27) T. Mori, K. Ayata, M. Fujimaki, T. Soejima and M. Kawahara: Tetsuto-Hagané, 62 (1976), S132.

28) H. Fujii and T. Ohashi: Tetsu-to-Hagané, 64 (1978), S646.

29) K. Narita, T. Mori, K.Ayata, J. Miyazaki, M. Fujimaki and T. Shiomi: Tetsu-to-Hagané, 64 (1978), S659.

30) M. Suzuki, S. Miyahara, T. Kitagawa, S. Uchida, T. Mori and K. Okimoto: Tetsu-to-Hagané, 78 (1992), 113.

31) J. W. Spretnak: Trans. Am. Soc. Met., 39 (1947), 569.

32) W. Kurz and D. J. Fisher: Fundamentals of Solidification, Trans Tech Publications Ltd., Zuerich, (1998), 293.

$33)$ A. Suzuki, T. Suzuki, Y. Nagaoka and Y. Iwata: J. Jpn. Inst. Met., 32 (1968), 1301.

34) T. Edvardsson, H. Fredriksson and I. Svensson: Met. Sci., 10 (1976), 298.

35) W. Ostwald: Lehrbruck der Allgemeinen Chemie, Vol. 2, Leipzig, Germany, (1896), 1.

36) S. Hiraki, M. Kawamoto, T. Murakami, M. Hanao and T. Watanabe: CAMP-ISIJ, 11 (1998), 185.

37) T. Umeda, N. Shu and T. Okane: CAMP-ISIJ, 9 (1996), 588. 